Received: February 16, 2017

Accepted: March 16, 2017

Published: March 21, 2017

\title{
Clinical Presentations of Acute Leukemia in Pediatric Emergency Department of Pakistan
}

\author{
Amna Jawaid ${ }^{1, *}$, Khubaib Arif $^{1}$, Nida Amjad $^{3}$ \\ ${ }^{1}$ Department of emergency medicine, Senior Instructor, Aga khan university hospital. \\ ${ }^{2}$ Department of emergency medicine, Senior Medical Officer, Aga khan university \\ hospital. \\ ${ }^{3}$ Department of Pediatrics and Child health, Resident Medical Office, Aga khan university \\ hospital.
}

*Corresponding author: Amna Jawaid, Senior Instructor, Department of emergency medicine, Aga khan university hospital,Tel: 03002646146; E-mail: Jawaid.amna@gmail.com

\section{Abstract}

\subsection{Objective}

To determine the frequency, clinical presentation and laboratory investigation of leukemia in children presenting first time in pediatric emergency department of tertiary care hospital.

\subsection{Study Design}

Descriptive study

\subsection{Place and duration of study}

Department of emergency medicine at Aga khan university hospital from January 2009 to December 2013.

\subsection{Method}

A retrospective Chart review of all pediatric patient from age of 1 months to 16 years of age, presenting first time in emergency room with signs and symptom and labs investigation suggestive of acute leukemia was done. After reviewing the record, a questionnaire was filled and data was analyzed using SPSS version 19.The results are presented as mean, frequency and percentage.

\subsection{Results}

A total of 102 medical charts were reviewed for children aged 1 month to 16 years presenting to the ED with clinical or laboratory suspicion of Leukemia. The median age of the children was 4.75 years with majority of them below 5 years of age $(57.8 \%)$.
Males $(66.7 \%)$ were the dominant population with Fever $(92.2 \%)$ the common presentation followed by weight loss (51\%) and pallor (51\%). B-Cell ALL was the most common sub-type followed by T-Cell ALL.

\subsection{Conclusion}

Early detection of childhood leukemia in ED has contributed to improved medical care for these children. Therefore the knowledge regarding various presentations and management of life threatening situations seen with leukemia is critical to the emergency caregiver.

\subsection{Keywords}

Acute leukemia; Presentation; Emergency room; Children

\section{Introduction}

Emergency department is one of the emerging department of the developing countries. Patient seen here are mostly belong to high acuity. Despite of this important diseases are diagnosed here as equipped with high diagnostic modalities. Leukemia is the most prevalent childhood cancer. The cause is not known but certain factors like host and environment is supposed to play role in pathogenesis [1].

Leukemia account for about 20,000 cancer diagnoses and over 10,000 annual deaths in the United States [3]. It constitutes $31 \%$ of childhood malignancies in children under 15 years old and $25 \%$ of childhood cancers in children less than 20 years of age [4]. Child with leukemia has very varied and nonspecific presentation causing delay in diagnosis. Delay in seeking care is considerably shorter than the delay in diagnosis [5].

Fever, bruises and pallor was the common presentation and B-Cell ALL was the most common sub-type followed by T-Cell ALL 
Table 1 Frequency of clinical presentation of suspected Leukemia patients presenting to Emergency department

\begin{tabular}{|l|l|l|}
\hline Symptoms & $\begin{array}{l}\mathbf{n = 1 0 2} \\
\mathbf{( 1 0 0 \% )}\end{array}$ & $\begin{array}{l}\text { Duration in } \\
\text { days } \\
\text { (Mean } \pm \text { SD) }\end{array}$ \\
\hline Fever & $94(92.2 \%)$ & $53.2 \pm 54.6$ \\
\hline Weight loss & $52(51 \%)$ & $38.5 \pm 35.4$ \\
\hline Rashes & $37(36.3 \%)$ & $7.1 \pm 6.4$ \\
\hline Pallor & $52(51 \%)$ & $38.9 \pm 35.2$ \\
\hline Abdominal Pain & $10(9.8 \%)$ & $10 \pm 8.9$ \\
\hline Bleeding & $24(23.5 \%)$ & $8.0 \pm 8.3$ \\
\hline Bone Pain & $29(28.4 \%)$ & $27.7 \pm 23.3$ \\
\hline Cough & $20(19.6 \%)$ & $19.9 \pm 28.2$ \\
\hline Dyspnea & $17(16.7 \%)$ & $14.7 \pm 20.5$ \\
\hline Headache & $3(2.9 \%)$ & $37.3 \pm 27.3$ \\
\hline Vomiting & $4(3.9 \%)$ & $10.0 \pm 8.9$ \\
\hline Abdominal distention & $6(5.9 \%)$ & $19.7 \pm 22.2$ \\
\hline Neck swelling & $2(2 \%)$ & $22.5 \pm 10.6$ \\
\hline Oral ulcers & $3(2.9 \%)$ & $5.67 \pm 1.1$ \\
\hline
\end{tabular}

observed by local study [15]. Children diagnosed with leukemia may present to either primary care physician or to the emergency physician. In developed countries survival of treated cancers has increased drastically. But in developing countries cure rate is still low because of delayed diagnosis [6]. To avoid missing the early diagnosis, knowledge of common presentation and management of leukemia is important to emergency care provider [7]. Early diagnosis and identification of prognostic markers leads to better outcome [8].

Data related to clinical presentation of acute leukemia from pediatric emergency department is not only missing from Pakistan. But also deficient record found from other countries. This study focus on the clinical presentation of childhood Leukemia that the emergency care provider are dealing in developing countries.

\section{Method}

Aga khan university hospital is one of a leading tertiary care hospital in Pakistan. It is teaching hospital with training of resident and fellows in various subspecialties. It also deals with patient of various subspecialties including pediatric hematology and oncology.

This was a descriptive study done over period of five years from January 2009 to December 2013. This study included 102 pediatric patients from age of 1 month to 16 years of age, presenting first time in emergency department with signs and symptom and laboratory investigation suggestive of Leukemia.

The data was retrieved through medical record and composed of three components (demographic, presenting symptoms, laboratory investigation and diagnosis. Demographic data include age, gender presenting symptoms include presence of fever, weight loss, bone pain, rashes, pallor, abdominal mass, bleeding, bone pain, cough, dyspnea, headache, seizure, behavioral changes cranial nerve dysfunction and endocrine dysfunction. Labs include complete blood count, peripheral smear, tumor ly-
Table 2 Laboratory parameters and diagnosis of suspected leukemia patients presenting to Emergency department

\begin{tabular}{|l|l|}
\hline Laboratory and radiological findings & $\mathbf{n}=\mathbf{1 0 2 ( 1 0 0 \% )}$ \\
\hline \multicolumn{2}{|c|}{ Laboratory Findings } \\
\hline Hb (g/dl) & $7.7 \pm 2.3$ \\
\hline TLC (*10E9/L) & $72.5 \pm 107.6$ \\
\hline Platelets (*10E9/L) & $66.8 \pm 111.8$ \\
\hline Serum K (mmol/L) & $4.05 \pm 0.73$ \\
\hline Serum Cr (mg/dl) & $0.54 \pm 0.42$ \\
\hline Serum Ca (mg/dl) & $8.7 \pm 0.85$ \\
\hline Serum Phosphorus (mg/dl) & $4.32 \pm 1.1$ \\
\hline Serum uric acid (mg/dl) & $5.11 \pm 3.11$ \\
\hline Hyperleukocytosis (TLC ł100) & $25(24.5 \%)$ \\
\hline Tumor Lysis Chest Xray Findings \\
\hline Bone Marrow for blast & $5(4.9 \%)$ \\
\hline \multicolumn{2}{|c|}{$102(100 \%)$} \\
\hline Normal & $79(77.5 \%)$ \\
\hline Infiltrates/consolidation & $16(15.7 \%)$ \\
\hline Pleural effusion & $4(3.9 \%)$ \\
\hline Both & $3(2.9 \%)$ \\
\hline \multicolumn{2}{|c|}{ CT scan Findings } \\
\hline CT Chest for mediastinal mass & $7(6.9 \%)$ \\
\hline Diagnosis & $\mathrm{n}=102(100 \%)$ \\
\hline B Cell All & $65(63.7 \%)$ \\
\hline T Cell All & $20(19.6 \%)$ \\
\hline AML & $15(14.7 \%)$ \\
\hline CML & $1(1 \%)$ \\
\hline Burkitt leukemia & $1(1 \%)$ \\
\hline
\end{tabular}

sis, bone marrow biopsy, CT/ X ray chest, CT Brain, CT abdomen.

Data was collected on the proforma and transferred into SPSS for analysis. Percentages and frequency used for descriptive statistics and mean and standard deviation used for continuous variables. $P$ value $\leq 0.05$ was considered significant.

\section{Results}

During period of 5 years, 81,151 children visited emergency room. About 154 children diagnosed with malignancy during investigation and out of this 102 patient diagnosed with acute leukemia. This makes acute leukemia $66.23 \%$ of malignancy. The median age of the children was 4.75 with IQR (2.00-7.25) with majority of them below 5 years of age (57.8\%). Males constitute the dominant population in study $(66.7 \%)$.

Fever (92.2\%) was the most common presentation among children followed by weight loss (51\%) and pallor (51\%) (Table 1). Laboratory data revealed average hemoglobin of $7.7 \pm 2.3$ with minimum of $3.4 \mathrm{~g} / \mathrm{dl}$. Tumor lysis was observed in $4.9 \%$ whereas hyperleukocytosis in 25 (24.5\%) children with the lowest TLC of $0.7 * 10 \mathrm{E} 9 / \mathrm{L}$ and highest being $459 * 10 \mathrm{E} 9 / \mathrm{L}$ (Table 2). Specific radiological imaging was conducted on all children presenting to ED depending on the presenting complaints (Table 2). Mediastinal mass was detected in $6.9 \%$ of patients with leukemia.

B-Cell ALL was the most common sub-type followed by T-Cell ALL (63.7\% and 19.6\% respectively) (Table 2). B-Cell ALL, AML and CML was common in younger age group $(<5$ year) where as T- 
Cell ALL and Burkitt leukemia was found more in older children ( $>5$ year). Males were the dominant population in all subtype of leukemia. Significantly male present with typical presentation as compared to females where majority of common presentation are missed.

\section{Discussion}

Leukemia though rare is one of the important causes of mortality in childhood. Presentation can be nonspecific mimicking those of benign conditions resulting in high probability of it being either missed or diagnosed at a later stage $[9,10]$. Its reported incidence is under estimated owing to a lack of diagnostic modalities in major part of the country. Increasing number of patients are now being diagnosed in emergency department because of high clinical suspicion and enhanced diagnostic tools available in the emergency department (ED) [3,11].

Our study reported children under 5 years of age as vulnerable group with male predominance. Almost similar statistics were seen in national and international studies [12-14]. B-cell ALL was the most common variety of leukemia diagnosed $(63.7 \%)$ followed by T-Cell ALL (19.6\%). This figure was higher than reported by one study in Iran where frequency of T-Cell was documented to be greater than B-Cell ALL, where as an approximately similar result was seen in one local study by Mushtaq et al. $[15,14]$. $8 \cdot 1 \%$ of all the patients diagnosed with leukemia had AML in a study by S Zaki et al in contrast to our study where $14.7 \%$ of patients had AML,where as another study reported its frequency to be $38 \%[3,16]$.

Fever was the most common presentation in children with suspected leukemia followed by weight loss and pallor. In contrast to a study by Pahloosye et al our study reported presentations that was similar to those observed by our colleagues in their experience [13-14,15,17]. Relevant laboratory parameters were also recorded for suspected leukemia. The mean Hemoglobin ( $\mathrm{Hb})$ observed was $7.7 \pm 2.3$. Similar results have been reported from other studies [12,14]. Hyperleukocytosis was observed in 24.5\% of our children. Muzzaffar et al observed hyperleukocytosis in $14 \%$ of children with acute leukemia in their study [18].

Early diagnosis plays important role in childhood leukemia as it leads to increased survival by timely treatment in early stage. Physicians should have a high index of suspicion and should explore the possibility of leukemia in children who have worrisome and/or ongoing signs and symptoms.

\section{Conclusion}

Early detection of childhood leukemia in ED has contributed to improved medical care for these children. This study also highlights the importance of emergency department in diagnosing important diseases like Leukemia in country like Pakistan.

\section{References}

1. Kadan-Lotticck NS, Epidemiology of childhood and adolescent cancer. In : Kleigman RM, Behrman RE, Jenson HB, Stanton
BF, Nelson textbook of pediatrics. 18th ed. philadelphia: W.B. Saunders 2007;2097-9

2. Jemal A, Siegel R, Xu J et al. Cancer statistics. CA Cancer J Clin. 2010;60(5):277-300.

3. Shahab F and Raziq F. Clinical presentation of acute Leukemia. JCPSP 2014;24(7):472-476.

4. Bethesda, MD. SEER Cancer Statistic Review, 1973-1999. National Cancer Institute 2000 p. 467.

5. Haimi M, Peretz Nahum M, Ben Arush MW. Delay in diagnosis of children with cancer: a retrospective study of 315 children. Pediatr Hematol Oncol. 2004;21(1):37-48.

6. James BO, Ajayi SO, Ogun OA et al. Factors influencing time to diagnosis of childhood cancer in Ibadan, Nigeria. Afr Health Sci. 2009;9(4):247-253.

7. Fragkandrea I, Nixon JA, Panagopoulou P. Signs and symptoms of childhood cancer: a guide for early recognition. American family physician. 2013;88(3):185-192.

8. Shabbir A. Childhood cancers: experience at a tertiary care hospital. JRMC. 2011;15(1):38-39.

9. Thulesius H, Pola J, Hakansson A. Diagnostic delay in pediatric malignancies-a population based study. Acta Oncol 2000;39(7): 873-876.

10. Bernbeck B, Wuller D, Janssen D et al. Symptoms of childhood acute lymphoblastic leukemia: red flags to recognize leukemia in daily practice. Klini Pediatr. 2009;221(6):369-373.

11. Kundra M. Epidemiologic findings of cancer detected in a pediatric emergency department. Clinica pediatr, 2009;48(4):404409.

12. De Sousa DWL, De Almeida Ferreira VF, Felix CHF et al. Acute lymphoblastic leukemia in children and adolescents: prognostic factors and analysis of survival. Rev Bras Hematol Hemoter. 2015;37(4):223-229.

13. Fadoo Z, Mushtaq N, Alvi S et al. Acute myeloid leukaemia in children: experience at a tertiary care facility of Pakistan." J Pak Med Assoc 2012;62(2):125-128.

14. Pahloosye A, Hashemi A, Mirmohamadai SJ et al. Presenting Clinical and Laboratory Data of Childhood Acute Lymphoblastic Leukemia. Iranian journal of Pediatric Hematology Oncology. 2011;1(3):71-77.

15. Mushtaq N, Fadoo Z, Naqvi A. Childhood acute lymphoblastic leukaemia: experience from a single tertiary care facility of Pakistan. J Pak Med Assoc. 2013;63(11):1399-1404.

16. Zaki S, Burney IA, Khurshid M. Acute myeloid leukemia in children in Pakistan: an audit. J Pak Med Assoc. 2002;52:247249.

17. Nakimbugwe, F. Clinical presentation and outcome of acute leukemias in children at uganda cancer institute (2008).

18. Haase R, Merkel N, Diwan O et al. Leukapheresis and exchange transfusion in children with acute leukemia and hyperleukocytosis. A single center experience. Klinische Padiatrie. 2009;221(6):374-378. 